\title{
USE OF TITANIUM AND ZIRCONIUM IN A CENTRIFUGALLY CAST HEAT RESISTANT STEEL
}

F.G. CABALLERO, P. IMIZCOZ, V. LOPEZ, L.F. ALVAREZ and C. GARCÍA DE ANDRÉS

Dr. F.G. Caballero (fgc@cenim.csic.es), Dr. V. López (vlopez@cenim.csic.es), L:F:

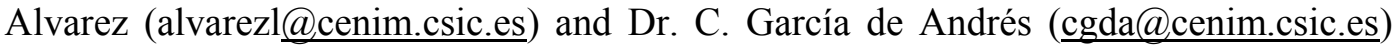
are in the Department of Physical Metallurgy, Centro Nacional de Investigaciones Metalúrgicas (CENIM), CSIC, Avda. Gregorio del Amo, 8, 28040 Madrid, Spain. P. Imizcoz (pimizcoz@scspain.com) is in Metallurgical Service Department at Schmidt+Clemens, Ctra. Estella-Vitoria Km. 12, 31280 Murieta, Spain. 


\begin{abstract}
Low carbon $25 \%$ Cr-35\% Ni steel (HP type steel) modified with titanium and zirconium has been produced by centrifugal casting. The different phases present in the as-cast and aged conditions were described by light optical and scanning electron microscopy with secondary electron imaging and energy dispersive spectroscopy (EDS). Results suggest that the use of titanium as a microalloying element reduces secondary precipitation during aging. Moreover, secondary precipitates in the microalloyed steel are much finer and more evenly distributed. On the other hand, zirconium oxides was found to be potential nucleation sites for primary titanium-rich carbides contributing to an optimum distribution of these carbides in the tubes. These differences together with the higher stability of the titanium containing primary carbides are responsible for the improvement on ductility and creep resistance found in this work.
\end{abstract}

Key words: Centrifugal casting, Heat resistant steels 


\section{Introduction}

In ethylene crackers and steam reformer plants there is a general requirement for high temperature resistance of the materials used. Since the 50's wrought materials such as INCO 800 and its different versions have been extensively used in outlet components ${ }^{1}$. Likewise, in the 70's these materials proved to be feasible to manufacture by centrifugal and static casting ${ }^{2}$. Thus, different cast alloys with improved creep and oxidation resistances were developed specifically for those manufacturing procedures. In this sense, an increase in the $\mathrm{C}$ content related to the casting process, and the addition of $\mathrm{Nb}$ to the cast alloys led to a significant improvement in the creep resistance of the alloy by means of primary precipitation of $\mathrm{Cr}$ and $\mathrm{Nb}$ carbides as well as increasing the precipitation events of $\mathrm{Cr}$ during aging $^{3}$. Further requirements from the industry for higher temperature applications of outlet component materials led to upgrade the already used alloys by the increase of $\mathrm{Cr}$ and $\mathrm{Ni}$ in the composition and to produce the $25 \% \mathrm{Cr}-35 \% \mathrm{Ni}$ HP type steels ${ }^{4,5}$. In this last development a low carbon $\mathrm{Nb}$ modified version of HP proved to be a good candidate as outlet component material.

The centrifugal casting process is a well known and reputed manufacturing procedure ${ }^{6}$. The main benefit in comparison with static casting is the achievement of higher degree purity in the alloys due to the centrifugal force generated during casting which leads to a floating effect that cleans the alloy from oxides and inclusions. Likewise, the control of the structure and refinement of grains improves the mechanical and oxidation properties of the centrifugally cast alloy as well as its weldability.

In this work, an improved centrifugally cast heat resistant alloy has been studied regarding the microalloying effect of titanium additions. Titanium will contribute to material strengthening promoting primary precipitation in the alloy. Likewise, 
zirconium has been added during the manufacturing process in order to obtain a synergistic effect of both microalloying elements on this alloy's properties. In this sense, the maximum effect of titanium on the precipitation hardening of heat resistant alloys is obtained. As a result an increase in creep resistance and significant values of ductility, vital in service, has been reached in the material. This improvement in the behaviour of the material at high temperature is related to the presence of titanium carbonitrides in the as-cast material and their influence on the secondary precipitation of chromium during aging in service.

\section{Experimental Procedure}

The chemical composition of the low carbon Fe-Ni-Cr alloys studied is listed in Table I. The alloys were produced by Schmidt+Clemens as centrifugally cast tubes of diameter ranging from 150 to $180 \mathrm{~mm}$ and wall thicknesses ranging from 18 to $22 \mathrm{~mm}$ by conventional procedure ${ }^{6}$. In centrifugal casting, a permanent mold is rotated about its axis at high speeds (300 to $3000 \mathrm{rpm}$ ) as the molten metal is poured. The molten metal is centrifugally thrown towards the inside mold wall where it solidifies after cooling. The inside diameter has more impurities and inclusions which can be machined away. Taking Steel A as reference and with the aim of improving mechanical properties, the

levels of $\mathrm{Nb}, \mathrm{Si}$ and $\mathrm{Mn}$ was reduced in Steel B. Regarding the $\mathrm{Nb}$ and $\mathrm{Si}$ effect, the formation of intermetallic niobium-nickel-silicides (G-phase) is expected to decrease the creep resistance of the cast material ${ }^{7,8}$. On the other hand, the role of $\mathrm{Mn}$ in the mechanical properties is not clear. In $\mathrm{Ni}$ and Fe base superalloys, this element exerts a slight positive effect on high temperature strength and creep, but it is detrimental to oxidation resistance ${ }^{9,10}$. Finally, titanium has been used as a microalloying element. 
Titanium will enhance the primary precipitation of carbonitrides during solidification. Likewise, a certain amount of ferrosilicon zirconium was added to Steel B during centrifugal casting. In fact, the remaining zirconium in the chemical composition of the alloy (100 ppm) can be considered as a residual element.

Longitudinal specimens of cast material of both alloys were aged in a muffle furnace at three different temperatures $\left(850,900\right.$ and $\left.1000{ }^{\circ} \mathrm{C}\right)$ for different times $(100,500$ and 1000 hours) before air cooling.

Optical and scanning electron microscopy (SEM) were used to examine the etched microstructures. Specimens were ground and polished using standard techniques, etched in oxalic acid and Murakami's ${ }^{11}$ reagent and examined using a Jeol JXA 820 SEM operated at $15 \mathrm{kV}$ and a field emission gun (FEG) Jeol JSM 6500f SEM for higher resolution characterisation. Both microscopes are equipped with an energy dispersed Xray detector (Röntec EDR288 and Oxford Inca, respectively).

Tensile testing was carried out on cast and aged circular specimens $(8.75 \mathrm{~mm}$ in diameter and $43.75 \mathrm{~mm}$ gage length) in accordance with ASTM E8 at a wide temperature range on a $200 \mathrm{kN}$ Frank machine at a crosshead speed of $0.005 \mathrm{~mm} \mathrm{~s}^{-1}$. Two specimens were tested for each condition.

Longitudinal specimens for creep test with a diameter of $8 \mathrm{~mm}$ were machined for the cast alloys from the middle of the wall thickness according to ASTM E139. All the samples were previously wheel true in the testing length in order to minimise the influence of surface defects on test results. Before testing, non-destructive dye checking was used to verify the surface quality of the creep specimens. Constant load tensile creep tests were performed in air over the 20-100 MPa stress range between 800 and $1050{ }^{\circ} \mathrm{C}$. The temperature during test was measured by three thermocouples attached to 
the gage length of the specimen, and was controlled within $\pm 3{ }^{\circ} \mathrm{C}$. The data were continuously read through inductive transducers. All the creep tests were run to failure.

\section{Results and Discussion}

\section{Microstructural characterisation of as-cast and aged material}

Figure 1 shows low magnification macrographs of centrifugally cast microstructures of the studied alloys. Two clearly defined regions are observed in the macrostructure of the centrifugal in cast tubes - columnar grains outside and fine equiaxed grains inside the tubes. These two features are common to the structures of centrifugally cast ferrous alloys. Likewise, Fig. 2 shows the precipitation of carbides on grain boundaries and inside austenite grains in the outer and inner regions of both tubes. The austenite matrix with the dendritic carbide network typical of this type of material is seen clearly in these micrographs. Slight differences in Fig. 2 regarding the amount of precipitates in the outer and inner regions of both materials are related to the different solidification speed in both grain morphologies, columnar and equiaxed, resulting from the centrifugal casting process.

In the as-cast condition, primary $\mathrm{Cr}$ and $\mathrm{Nb}$ carbides precipitate on both steels across the wall thickness. In the classic HP composition, these precipitates are expected to be the $\mathrm{M}_{7} \mathrm{C}_{3}$ and $\mathrm{MC}^{12}$. Likewise, evenly distributed blocky titanium carbonitrides were observed inside austenite grains in the microalloyed steel. Moreover, complex niobiumtitanium-chromium carbides were detected in the grain boundary as Fig. 3a illustrates. Complementary, Fig. 3.b shows a magnified view and the EDX spectra of very fine 
chromium and niobium carbides that surround grain boundaries in the titaniumcontaining steel. With the addition of titanium, a significant fraction of the total carbon is consumed by the titanium-containing carbides at temperatures higher than those at which the chromium carbides precipitate. As a consequence, a higher $\mathrm{Cr} / \mathrm{C}$ ratio is present during secondary precipitation.

It is believed that occasionally residual zirconium oxides at a sub-micrometric scale may become a suitable nucleation site for titanium carbide precipitation ${ }^{13}$. In the same manner, chromium oxides have been observed as nucleation sites of blocky titanium carbonitrides (See Fig 4).

The aging effect of temperature and time on the above described microstructures is shown for the microalloyed steel in Fig. 5. The secondary precipitation decorates the austenitic matrix preferentially around grain boundary carbides. Those precipitates were identified as $\mathrm{M}_{23} \mathrm{C}_{6}$ chromium carbides. On the other hand, primary carbides, originally chromium-niobium-titanium carbides tend to coalesce and globularise during aging. In general, it is observed that secondary precipitation is slightly higher in the outer than in the inner region of the tube, due to the slightly lower amount of primary precipitates in the columnar region. G-phase was not observed. Titanium seems to inhibit and control the $(\mathrm{NbTi}) \mathrm{C}$ transformation to G-phase as Alemida et al. reported ${ }^{8}$.

Figure 6 shows a comparison of the resulting aging microstructures at $900{ }^{\circ} \mathrm{C}$ for $1000 \mathrm{~h}$ in both materials. In this case, samples were etched with Glyceregia reagent to reveal general structure and carbides ${ }^{11}$. Micrographs suggest that the use of titanium as a microalloying element reduces the degree of secondary precipitation during aging. Moreover, secondary precipitates in the microalloyed steel are much finer and more evenly distributed. Fig. 4 shows an example of FEG-SEM image obtained for the alloy containing microalloying additions in aged condition, where blocky primary titanium 
carbides and fine cuboids-shaped and acicular secondary chromium carbides are observed. Figure 7 shows a magnified view of the secondary chromium-niobium carbides in the microalloyed steel.

Differences in secondary carbide distribution on both steels must be related to the less precipitation events that occur around primary carbides in the microalloyed material. The higher carbide forming activity of titanium in primary carbides reduces the amount of carbon retained in the surrounding austenite available for further precipitation events. In this sense, it can be concluded that zirconium indirectly affects aging properties promoting primary precipitation of carbides containing titanium as a metallic element in the microalloyed steel.

\section{Ductility after aging and creep resistance}

Comparison of ductility after aging and creep resistance of both materials is represented in Fig. 8. The rupture ductility shows a gradual decrease, increasing with time and temperature. It is clear from Fig. 8.a graphs that the use of titanium as a microalloying element significantly improved ductility after aging. This is particularly beneficial for the use of this material in outlet components of furnaces.

On the other hand, Fig. 8.b represents the allowable stress to rupture as a function of temperature for a defined time to rupture of 100,000 hours for both materials in comparison to the creep resistance of INCOLOY $800 \mathrm{H}$ commercial steel ${ }^{14}$. The creep rupture data were basically analyzed and fitted to a regression equation of logarithmic stress using the time-temperature parameter of Larson-Miller ${ }^{15}$. This representation suggests that the microalloyed steel exhibits a higher creep resistance than that in the 
other two steels. The improvement of creep resistance in the microalloying steel without detrimental effect on the ductility is remarkable.

These results are related to the aging microstructural changes promoted by the microalloying additions. A much finer and more even distribution of secondary precipitates together with the higher stability of the titanium-containing primary carbides is responsible for the improvement in ductility and creep resistance. The interface between the G-phase and the matrix is a preferential site for the occurrence of creep damage ${ }^{16,17}$. In this sense, the formation of creep voids is minimised in the microalloyed steel due to the absence of G-phase in the aged microstructure. In this sense the use of microalloying elements such as titanium and zirconium has proved to be beneficial to the key properties of these alloys and for high temperature application.

\section{Conclusions}

An improved centrifugally cast heat resistant alloy has been developed using titanium as a microalloying element. Titanium enhances primary precipitation of carbonitrides during solidification contributing to precipitation strengthening. Likewise, zirconium has been used during the casting process in order to obtain a synergistic effect together with the addition of titanium.

Mechanical properties results have proved that the addition of both elements is beneficial for high temperature applications. The improvement of creep resistance in the microalloying steel without detrimental effect on the ductility is remarkable. These results are explained by the microstructural changes promoted during aging by titanium and zirconium. In contrast to the non-microalloyed steel, a much finer and more even 
distribution of secondary precipitates together with a higher stability of the titaniumcontaining primary carbides is reached in the steel containing microalloying additions.

On the other hand, X-ray analysis has shown that zirconium oxides enhance the nucleation of titanium-rich carbides. This contributes to a fine and evenly dispersed distribution of primary carbides in the cross section of the tubes.

\section{Acknowledgements}

Authors acknowledge financial support from the Ministerio de Ciencia y Tecnología (MCyT) (Proyecto-MAT2000-0412-P4-02). Schmidt+Clemens' author would also like to thank his management for permission to publish this paper. 


\section{References}

1) K. D. Barr and H. Zickler: Chemie-anlagen und Verfahren, 1989, 6, 2.

2) C. M. Schillmoller and S. B. Parks: Proc. of 1996 Annual Safety in Ammonia Plants and Related Facilities Symposium, AIChE, Boston, 1996.

3) T. Shibasaki, T. Mohri and K. Takemura: Proc. of 2000 Annual Safety in Ammonia Plants and Related Facilities Symposium, AIChE, Seattle, 2000, 40.

4) R. Gommans, H. Schrijen, J. Sundermann, W. Steinkusch and W. Hering: Proc. of VDEh Annual Symposium on Heat Resistant and Creep Resistant Steels, Stahlinstitut VDEh, Düsseldorf, 2000.

5) R. J. Gommans: Proc. of $5^{\text {th }}$ Schmidt and Clemens Group Symposium, Schmidt+Clemens, Selangor, 2002.

6) ASM Handbook, Formerly Ninth Edition, Metals Handbook, vol. 15, ASM International, USA, 1998, 296.

7) J. J. Hoffman: Proc. of Corrosion'2000, NACE International, Houston, 2000, 512.

8) L. H. de Almeida, A. F. Ribeiro and I. Le May: Materials Characterisation, 2003, 49, 219-229.

9) ASM Specialty Handbook-Heat Resistant Materials, eds. by J. R. Davis and Davis and Associated, ASM International, USA, 1997, 236.

10) ASM Specialty Handbook-Heat Resistant Materials, eds. by J. R. Davis and Davis and Associated, ASM International, USA, 1997, 309.

11) ASTM E-407 in Annual Book of ASTM Standards 2006, Volume 03.01, ASTM International, USA, 2006, 483.

12) G. D. A Soares, L. H. de Almeida, T. L. da Silveira and I. Le May: Materials Characterization, 1992, 29, 387-396. 
13) C. Capdevila, F. G. Caballero, C. García-Mateo and C. García de Andrés: Mater. Trans., 2004, 45, 2678-2685.

14) ASTM B 408, in Annual Book of ASTM Standards 2006, Volume 02.04, ASTM International, USA, 2006, 334.

15) H. E. Boyer: Atlas of Creep and Stress-Rupture Curves, ASM International, USA, 1997, 3.1.

16) L. H. de Almeida, P.R.O Emygdio, I. Le May and F. C. Ferraz: Microstructural Science, Vol. 24, eds. by M. G. Burke, E. A. Clark and E. J. Palmiere, Materials Park, ASM, 1996, 193.

17) A. A. Wahab and M. V. Kral: Mater. Sci. Eng. A, 2005, 412, 222-229. 
Table 1.- Mean Chemical Composition (mass-\%).

Fig. 1: Low magnification micrographs of centrifugally cast microstructures: a) Steel A and b) Steel B. O and I stands for outer and inner regions of the tube.

Fig. 2: Optical micrographs of as-cast microstructures: a) Steel A and b) Steel B. Outer region. Murakami reagent.

Fig. 3: FEG-SEM micrographs and EDX spectra of primary carbides in as-cast microstructure of Steel B: a) Titanium and niobium carbide precipitated in grain boundaries and b) very fine chromium and niobium carbides surrounding grain boundaries (because of the small size of both precipitates, EDX spectra may contain some chemical information from the matrix).

Fig. 4: FEG-SEM micrographs and EDX spectra of titanium oxides acting as nucleation site of blocky titanium carbonitrides in aged microstructure of Steel B.

Fig. 5: Optical micrographs of microstructures of Steel B obtained after aging at: a) 850 ${ }^{\circ} \mathrm{C}$ for 1000 hours; b) $900{ }^{\circ} \mathrm{C}$ for 100 hours; c) $900{ }^{\circ} \mathrm{C}$ for 500 hours; and $900{ }^{\circ} \mathrm{C}$ for 1000 hours. Inner region. Murakami reagent.

Fig. 6: Optical micrographs of microstructures obtained after aging at $900{ }^{\circ} \mathrm{C}$ for 1000 hours in a: a) Steel A and b) Steel B. Inner region. Glyceregia reagent. 
Fig. 7: FEG-SEM micrographs and EDX spectra of secondary carbides precipitated in microstructure obtained after aging at $900{ }^{\circ} \mathrm{C}$ for $1000{ }^{\circ} \mathrm{C}$ in Steel B. Because of the small size of both precipitates, EDX spectra may contain some chemical information from the matrix.

Fig. 8: Mechanical properties: a) ductility represented by elongation to rupture in tensile test as a function of parametric aging and b) creep resistance represented by average stress to rupture for 100,000 hours as a function of temperature. 
Table 1.- Mean Chemical Composition (mass-\%)

\begin{tabular}{cccccccccc}
\hline Steel & $\mathbf{C}$ & $\mathbf{S i}$ & $\mathbf{M n}$ & $\mathbf{C r}$ & $\mathbf{N i}$ & $\mathbf{N b}$ & $\mathbf{T i}$ & $\mathbf{Z r}$ & $\mathbf{N}$ \\
\hline $\mathrm{A}$ & 0.13 & 1.3 & 1.2 & 24.8 & 37 & 0.7 & - & - & 0.036 \\
\hline B & 0.13 & 0.6 & 0.3 & 24.8 & 37 & 0.3 & 0.1 & 0.1 & 0.037 \\
\hline
\end{tabular}




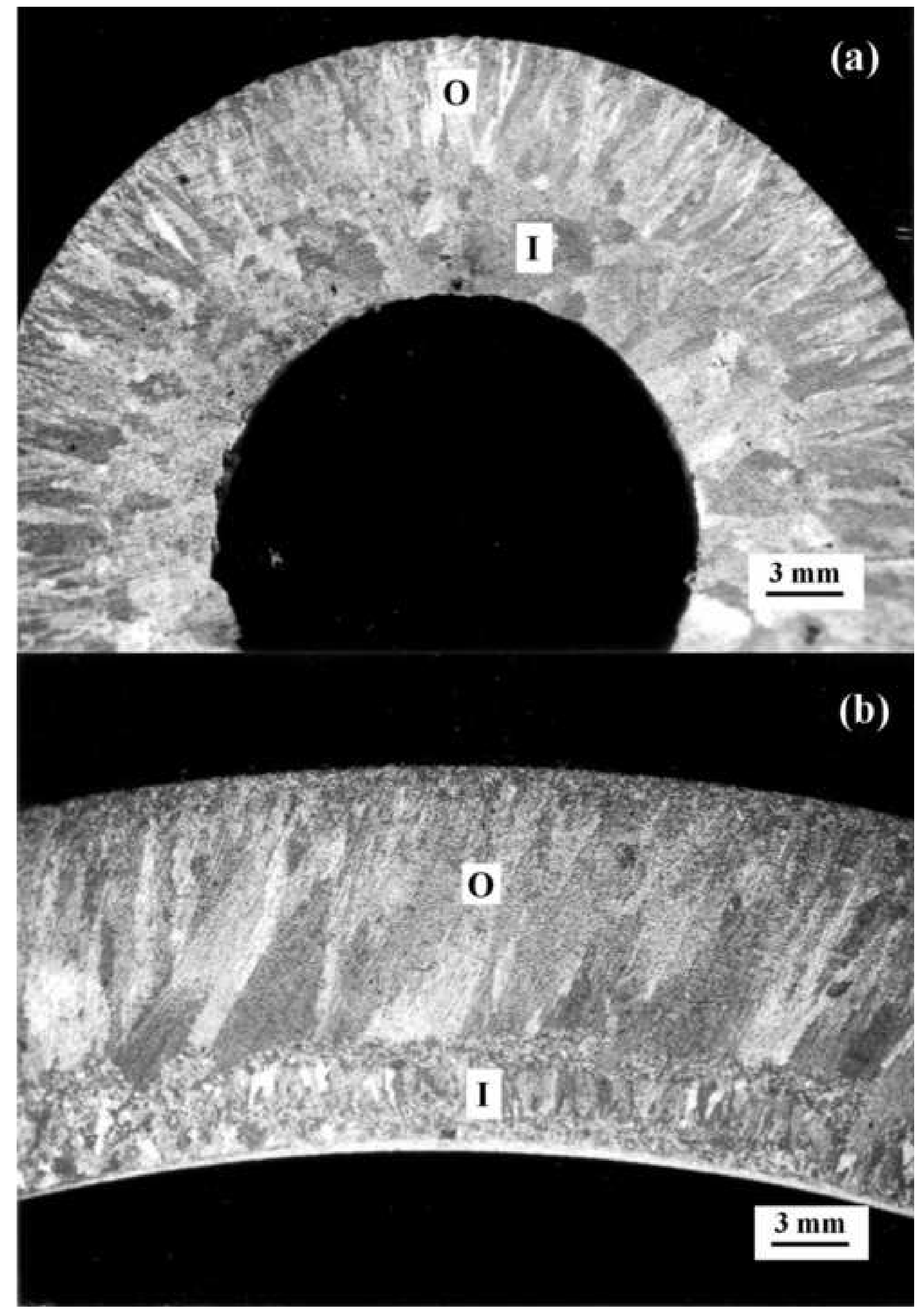

Figure 1

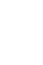
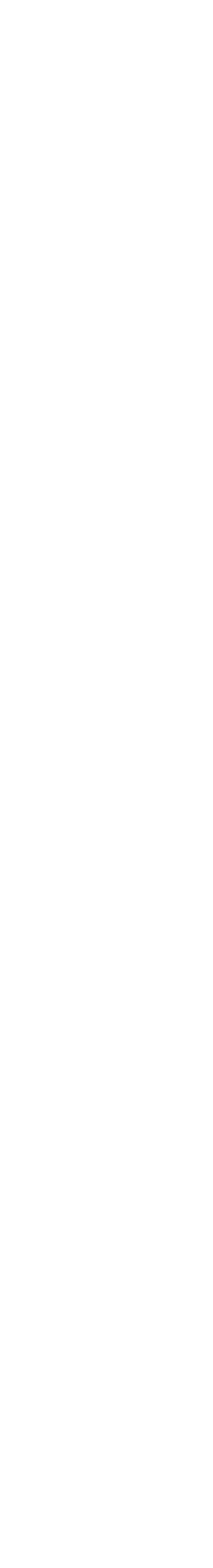
Non-colour figure

Figure 2

(a)

(b)

50 มี⿴囗十
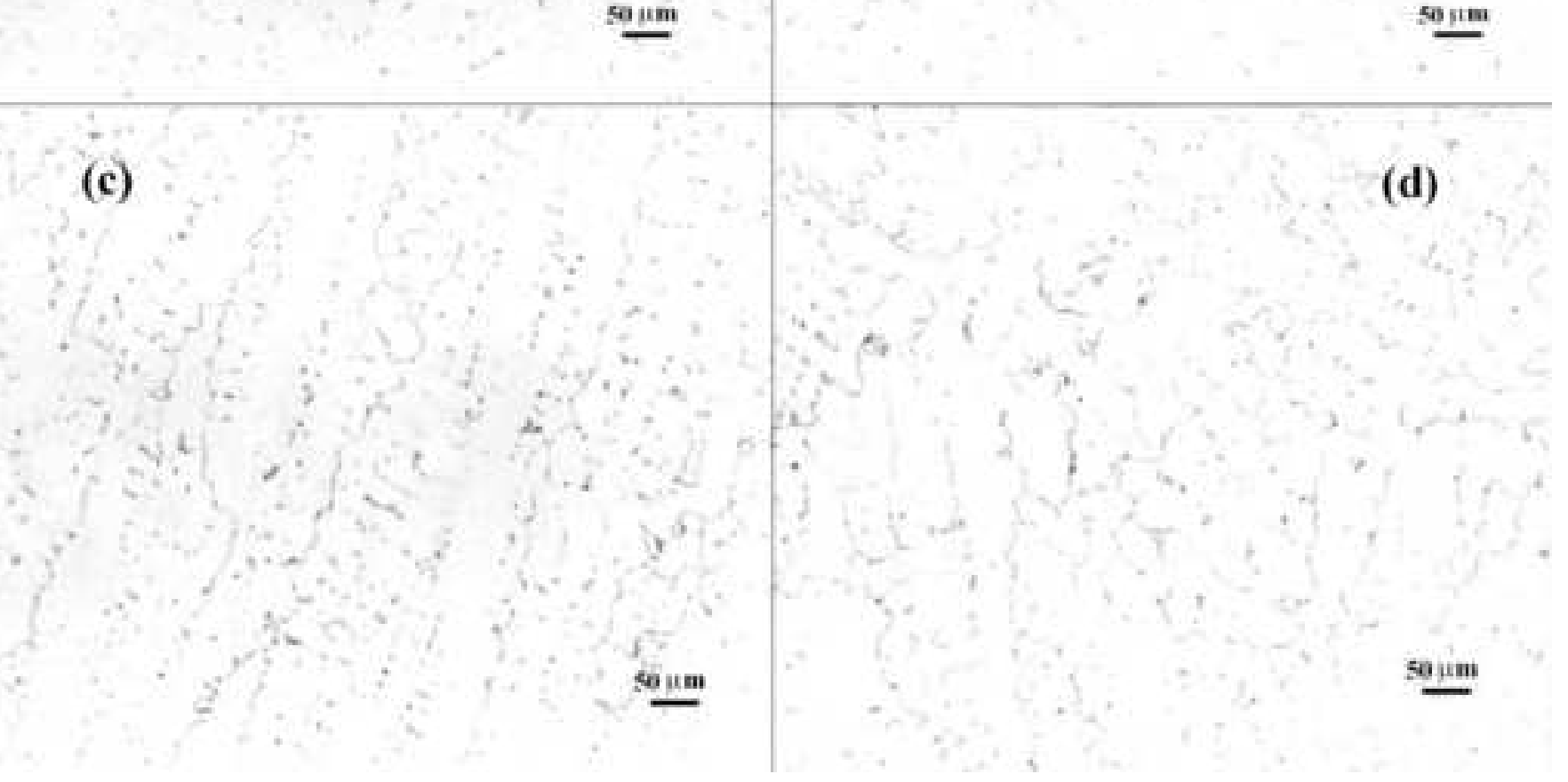
Figure 3

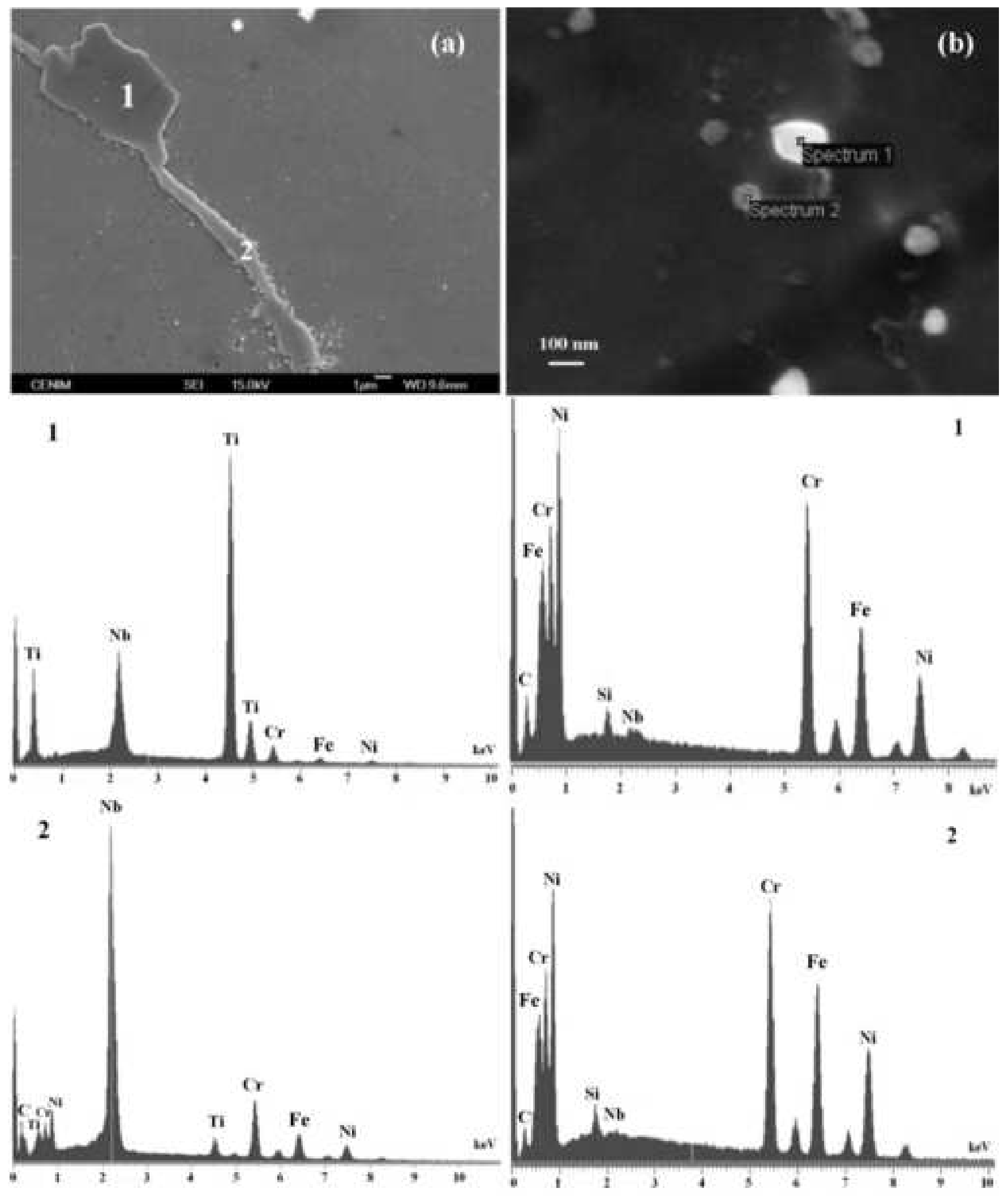


Figure 4

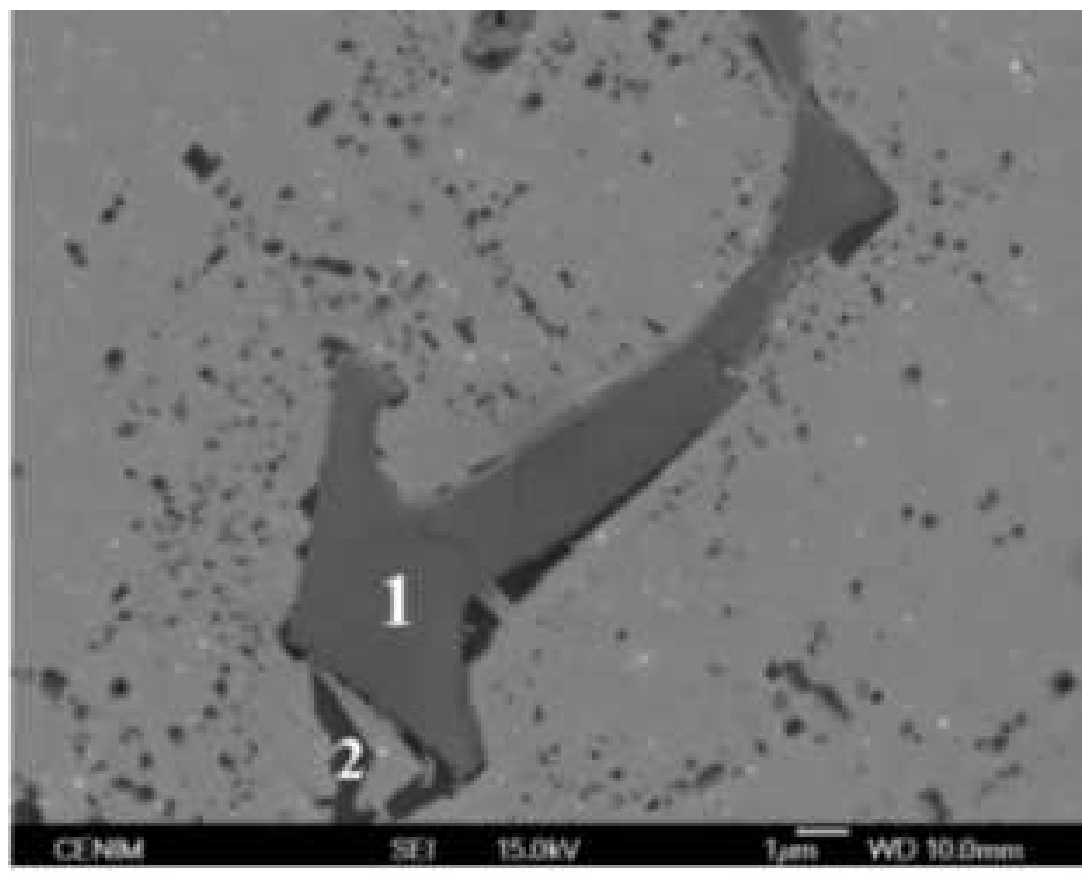

II
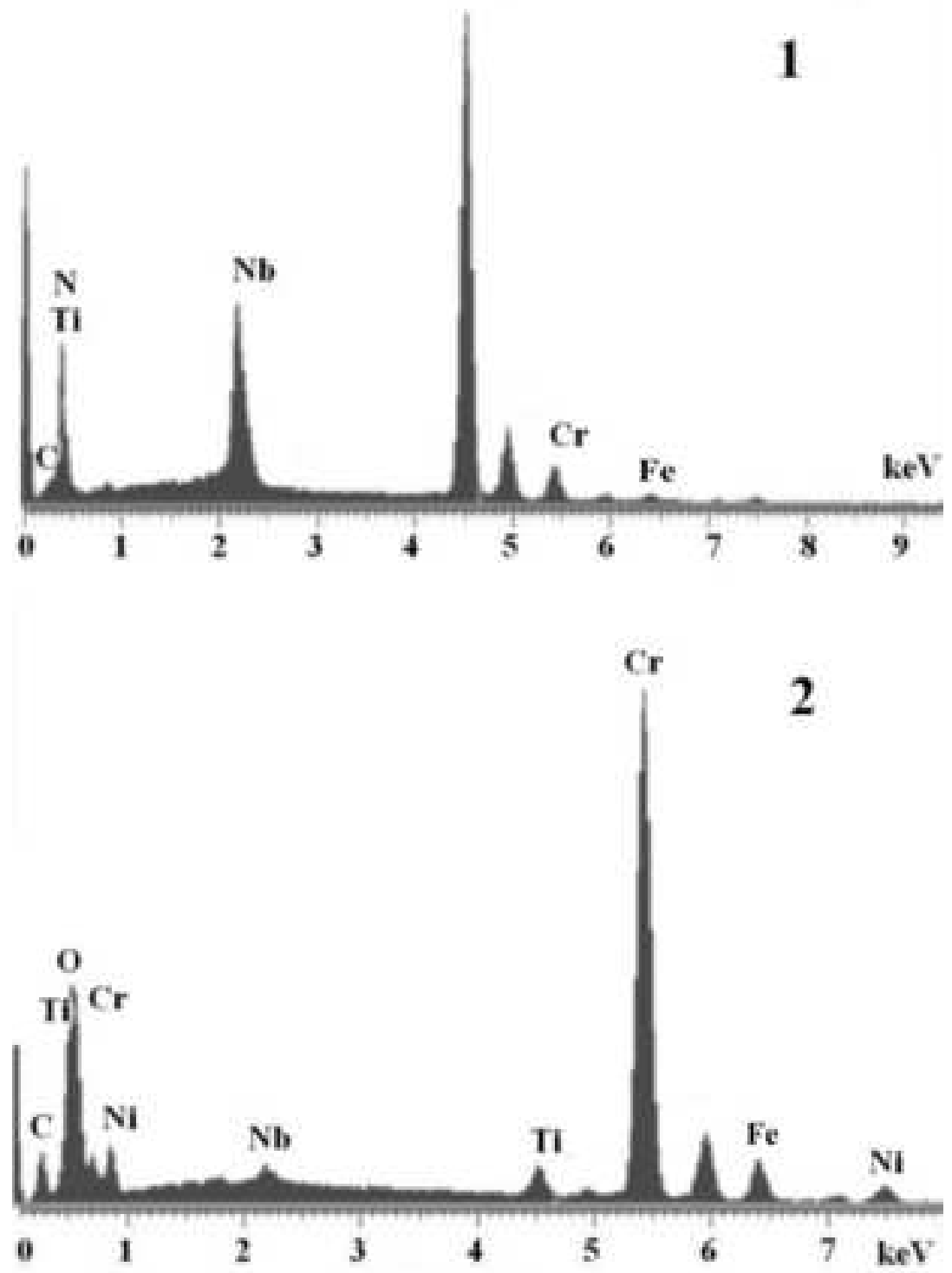
Figure 5

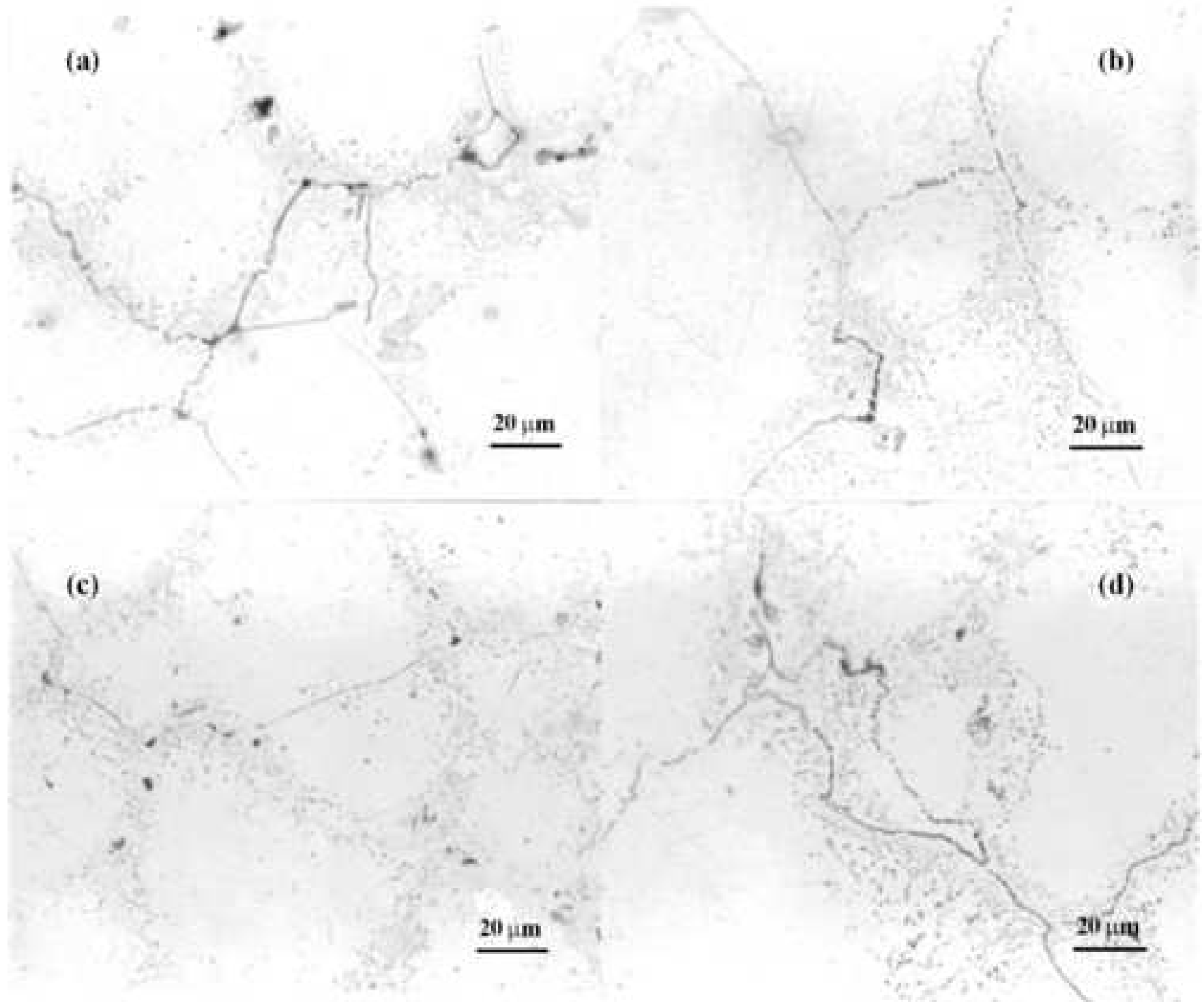


Figure 6

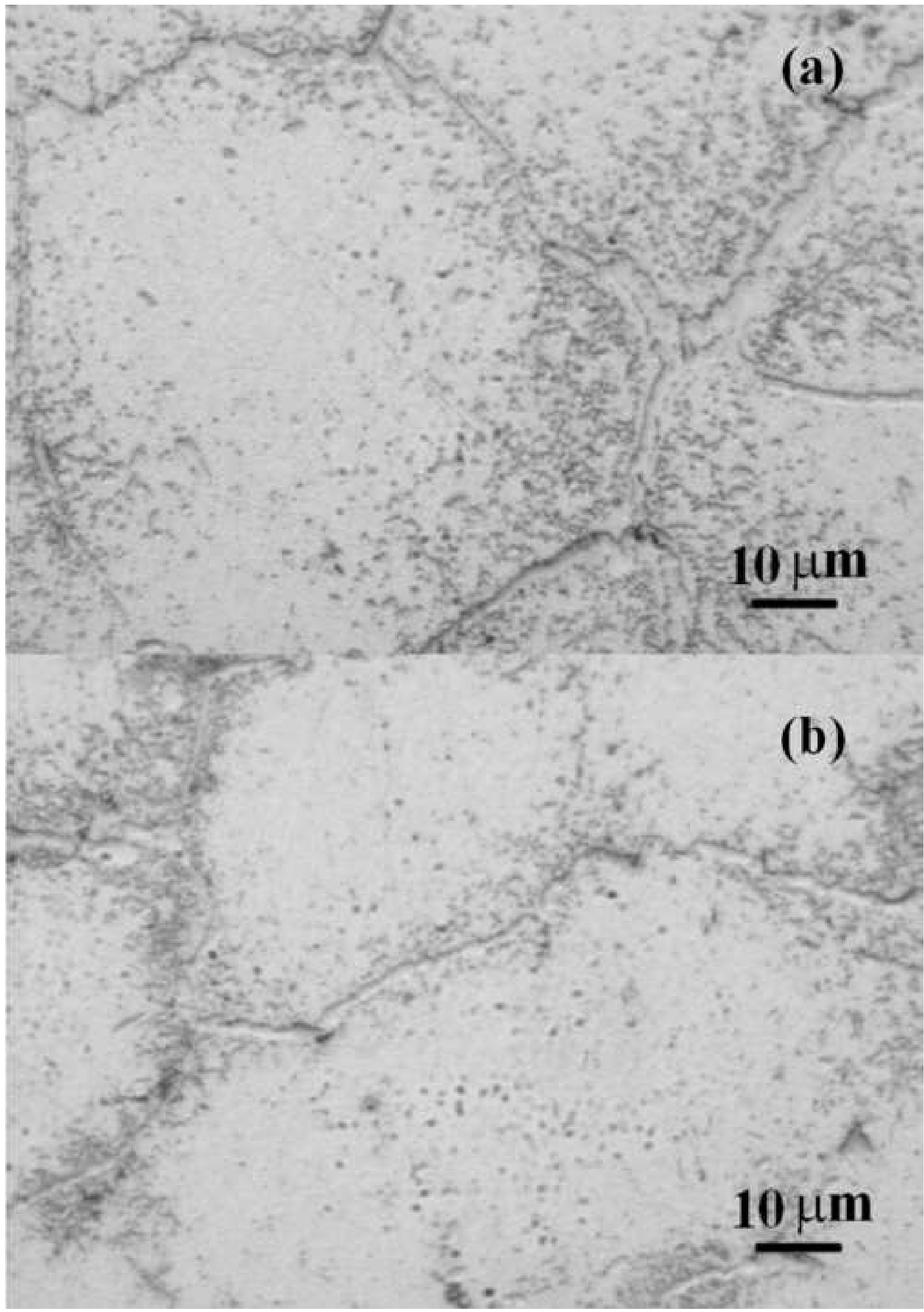


Figure 7
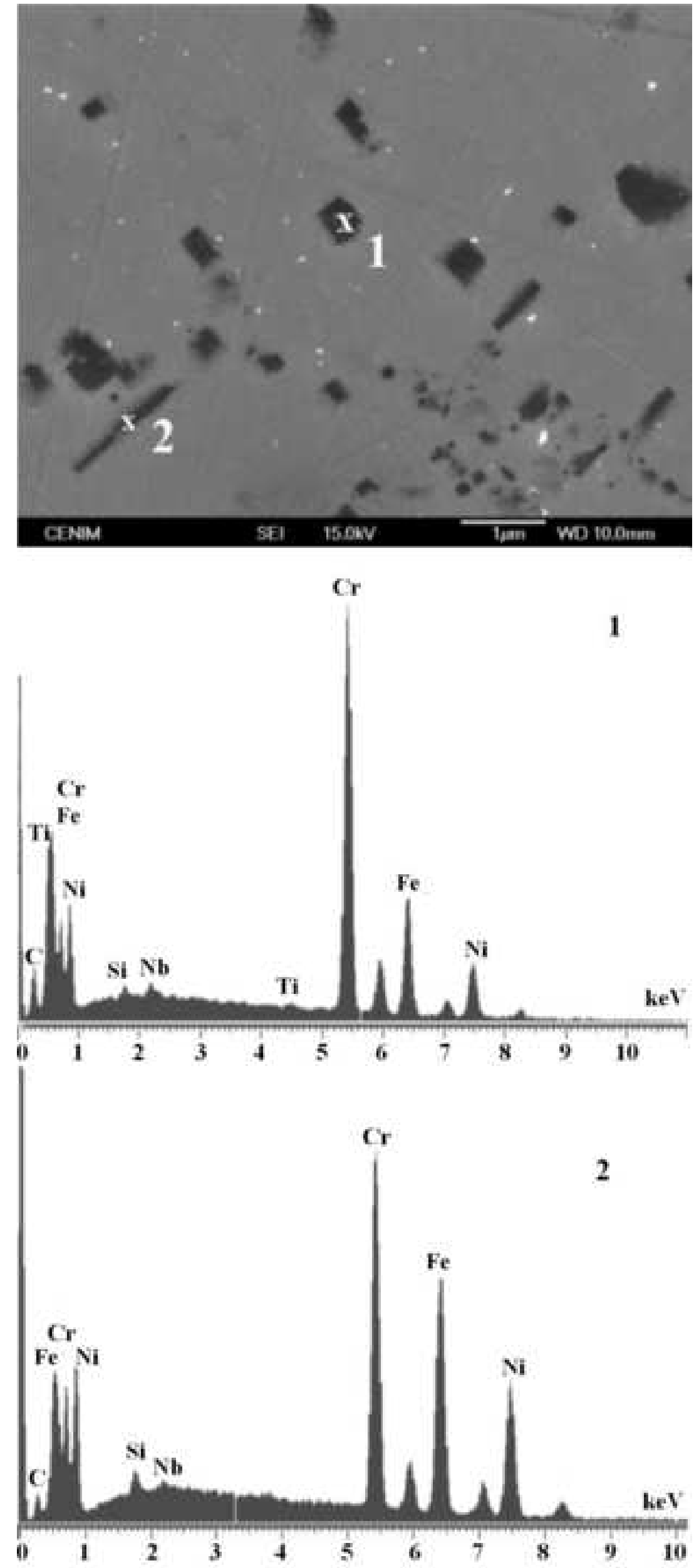

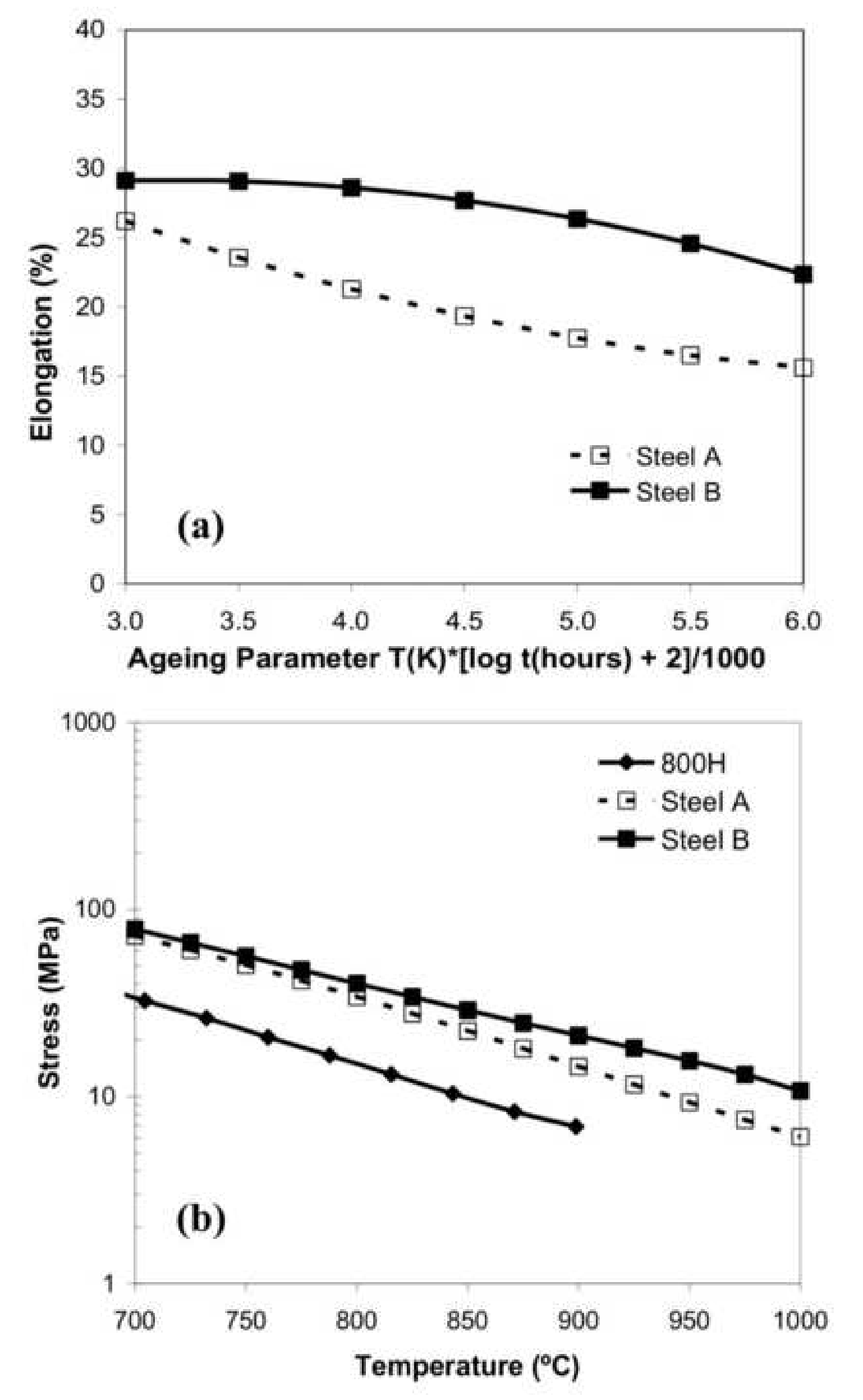

Figure 8

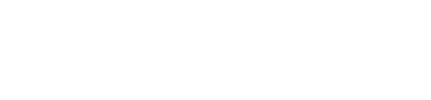

dod
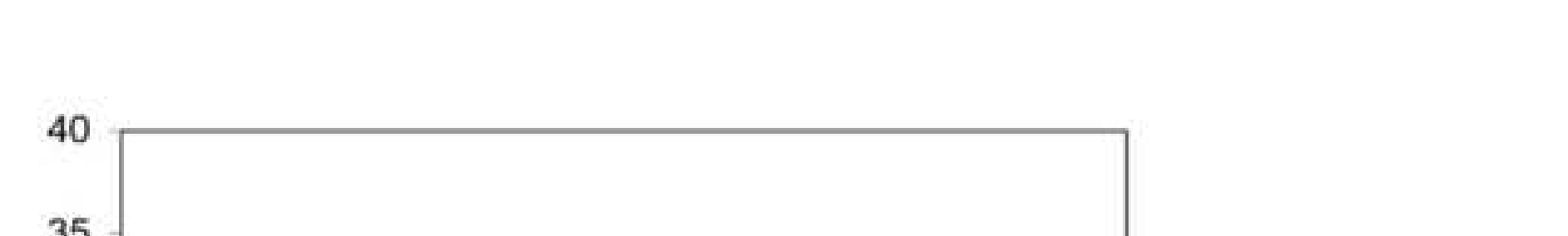